ARTIGO

\title{
Formação continuada de professores - professores excelentes: proposições do Banco Mundial
}

\author{
Julio Antonio Moreto
}

\section{RESUMO}

Estudamos a formação continuada de professores nas ações do Banco Mundial, conforme o Relatório Anual de 2018, e do Training teachers on the job: what works and how to measure it. Explicitamos a globalização pela teoria da ocidentalização como possibilidade explicativa, além de a formação ser entendida como formação profissional em alternância: articulação entre trabalho (prática) e estudos, compreendendo: a teoria do capital humano pela soma de aptidões e saberes, fonte de capacidade produtiva; a pedagogia das competências e a performance da escola, pelas avaliações externas; o treino de técnicas para ações futuras; o domínio da tecnologia; a preparação para o trabalho; o acompanhamento da sala de aula; e a adequação à prescrição de modelos que orientam os sistemas de acordo com as necessidades da globalização, como os professores, pelo treino e pela técnica.

PALAVRAS-CHAVE

formação continuada de professores; Banco Mundial; globalização.

'Universidade Estadual de Campinas, Campinas, SP, Brasil. 


\section{CONTINUED TEACHER TRAINING - EXCELLENT TEACHERS: PROPOSITIONS OF THE WORLD BANK}

\section{ABSTRACT}

We studied the Continued Education of Teachers, in the actions of the World Bank, Annual Report/2018 and the Training Teachers on the Job What Works and How to Measure It. We explain globalization, through the theory of westernization, as an explanatory possibility. Training understood as professional training in alternation: articulation between work (practice) and studies, comprising: the theory of human capital by the sum of skills and knowledge, source of productive capacity; the pedagogy of competences and school performance, by external evaluations; techniques training for future actions; field of technology; preparation for work; monitoring of the classroom; and adequacy to the prescription of models, guide systems in adapting to globalization needs, such as teachers, through training and technique.

KEYWORDS

continuing teacher education; World Bank; globalization.

\section{FORMACIÓN CONTINUADA DE PROFESORES - PROFESORES EXCELENTES: PROPOSICIONES DEL BANCO MUNDIAL}

\section{RESUMEN}

Estudiamos la Educación Continua de Profesores, en las acciones del Banco Mundial, el Informe Anual/2018 y la Training teachers on the job: what works and how to measure it. Explicamos la globalización, a través de la occidentalización, como una posibilidad explicativa. Formación entendida como formación profesional alterna: articulación entre trabajo (práctica) y estudios, que comprende: la teoría del capital humano por la suma de habilidades y conocimientos, fuente de capacidad productiva; la pedagogía de competencias y rendimiento escolar, mediante evaluaciones externas; técnicas de formación para acciones futuras; campo de la tecnología; preparación para el trabajo; seguimiento del aula; y adecuación a la prescripción de modelos, sistemas de guía para adaptarse a necesidades de la globalización, como los docentes, a través de capacitación y técnica.

formación continua de profesores; Banco Mundial; globalización. 


\section{INTRODUÇÃO}

Esta pesquisa teve como objetivo estudar as concepções e dinâmicas de formação continuada de professores propostas pelo Banco Mundial no contexto da globalização. Para tanto, utilizei documentos produzidos nos últimos anos, mais diretamente relacionados com o tema da pesquisa: o Relatório Anual do Banco Mundial de 2018, ${ }^{1}$ sobre $O$ desenvolvimento mundial: aprendizagem para realizar a promessa da educação; o estudo de Popova, Evans e Arancibia (2016), Training teachers on the job: what works and how to measure it; e o estudo de Burns e Luque (2014), Professores excelentes: como melhorar a aprendizagem dos estudantes na América Latina e no Caribe.

Pesquisar documentos é uma metodologia presente na minha formação profissional. $\mathrm{Na}$ carreira de mais de 30 anos de trabalho na escola pública, nos últimos 20 anos com formação continuada de professores, questionava a origem das políticas para a área. Um dos organismos internacionais que apresenta propostas de políticas educacionais aos países do sul é o Banco Mundial, o qual é um ator político a se considerar para a compreensão sobre o trabalho e a formação de professores.

Interroguei nos documentos as implicações da globalização nas concepções de formação continuada de professores e de trabalho docente. Para diferentes autores, ${ }^{2}$ a formação tem reflexos imediatos sobre os resultados escolares. Os diversos países, pelas mudanças sociais e culturais, ao empreenderem as reformas educacionais, concebem a formação continuada como prioridade para atender às necessidades estruturantes de reformas. Compreendo a formação de professores como formação profissional que se alterna entre tempo de trabalho (a prática docente) e os estudos teóricos-metodológicos.

Duas hipóteses orientam-me. A primeira é a de que há uma racionalidade, construída no processo de globalização (Ianni, 1996, p. 139). Entendo a racionalidade como produto histórico-social associado à produção, à empresa, ao mercado. Ela informa as propostas de formação continuada de professores oriundas do Banco Mundial. A segunda hipótese, derivada da primeira, é de que há um padrão na forma de realizar a formação entendida como treinamento e aquisição de técnicas de ensino e de aprendizagem.

Os documentos produzidos pelo Banco Mundial estão em acesso aberto à pesquisa e contribuem para as discussões sobre políticas de desenvolvimento (Popova, Evans e Arancibia, 2016). Bastos e Rocha (2017, p. 323), ao fazerem a crítica aos documentos do Banco Mundial, afirmam serem estes componentes da manutenção da lógica do mercado defendida pelo banco. Os documentos expressam uma visão sobre áreas e políticas específicas com a finalidade de adequar os países às orientações do Banco Mundial e, por conseguinte, ao mercado.

Os documentos coletados e analisados consistem em registros da realidade determinados historicamente pelo momento e pelo local, fornecem informações

1 Utilizo aqui o termo Relatório/2018.

2 Como exemplo: Canário (2001), Ferreira (2006), Freitas (2002, 2007, 2012, 2014), Gatti (2008), Gatti e Barreto (2009), Imbernón (2001) e Kuenzer (1999). 
ou são provas para essas mesmas informações. Podem se constituir em documentos escritos, orais e iconográficos (Queiroz, 1999, p. 21). Indaguei-os acerca das concepções de formação e trabalho docente.

Os documentos foram escolhidos pela relevância na construção e manutenção das relações de dominação dos Estados Unidos no processo de globalização (Ianni, 2003), que homogeneíza as ações dos "países do sul". O processo de homogeneização é compreendido por Ianni (2003) como forma de garantir a perpetuação da ocidentalização do mundo. Entende-se a ocidentalização como a predominância da lógica do mercado e da economia de países como Estados Unidos e da Europa Ocidental em todas as esferas da vida social. A ocidentalização - apoiada em organismos internacionais (como o Banco Mundial) facilitadores do comércio mundial — relega aos chamados "países do sul" políticas assistencialistas, para a sobrevivência dos Estados Unidos e da Europa Ocidental (Ianni, 2003, p. 84).

A globalização é um padrão hegemônico da economia e, por conseguinte, do mercado desde 1920, especialmente no que se refere às relações entre norte e sul, centro e periferia (Ianni, 1999, 2003). Essa noção permite entender as reformas neoliberais implementadas com o chamado Consenso de Washington, da década de 1980 - reformas formuladas pelas elites tecnocráticas neoliberais. A globalização concebe particularidades e descontinuidades entre as nações. Uma das características é a transnacionalização da economia mundial, levada a efeito pelos conglomerados multinacionais (Lima, 2015, p. 416).

As orientações do Banco Mundial são portadoras da nova ordem mundial, que se constitui pela transnacionalização da economia. Por os conglomerados serem multinacionais e multilocalizados, não se confirmam enquanto lógica de determinado país ou região.

Pela ótica da economia de mercado, faz-se preciso formar um novo trabalhador. A escola é o local privilegiado para formar a mão de obra futura. $\mathrm{Na}$ formação do trabalhador com habilidades intelectuais mais diversificadas e flexíveis, o professor, também, necessita ser formado.

Com base nos autores citados anteriormente, a formação de professores, de modo geral, é uma ferramenta que age diretamente sobre os resultados escolares. Em face das mudanças sociais e culturais, constitui prioridade em diferentes reformas educacionais e em diversos países. A noção de formação ao longo da vida foi desenvolvida nos anos de 1990, por meio de organismos internacionais como a Organização das Nações Unidas para a Educação, a Ciência e a Cultura (UNESCO) e a Organização para a Cooperação e o Desenvolvimento Econômico (OCDE), esta última, conforme sua página na web, com o objetivo de instaurar políticas para o crescimento e desenvolvimento do mercado, na busca pelo bem-estar social (apud Cury, 2017, p. 18).

Apresentam-se a UNESCO e a OCDE como o thinking tank, o reservatório para ideias. Atribuem-se à OCDE a "reforma da matemática moderna" e as ideias de "qualidade da educação", de "economia do saber" e de "formação ao longo de toda a vida" - questões centrais para o pensamento neoliberal em relação à educação. No caso da OCDE, sua criação deve-se à promoção da economia de mercado (Charlot, 2007, p. 133). São organismos internacionais afeitos à manutenção da 
lógica mercantil que veem na educação, de maneira especial na formação continuada de professores, a possibilidade de manutenção desse padrão, levando em conta a abrangência do trabalho do professor e, por conseguinte, da escola.

A formação ao longo da vida substituiu a concepção de formação permanente, num contexto em que se considerava (ainda se considera) a formação inicial como insuficiente para o exercício profissional da docência. A noção de formação permanente deu lugar à concepção de formação contínua e desenvolve-se fora e dentro do sistema escolar. Nessa dimensão, a formação continuada inscreve-se nas relações de trabalho nas instituições educacionais. Tomo a noção de formação profissional como aquela na qual se adquirem saberes específicos para se inserir na divisão social e técnica do trabalho, com conhecimentos reconhecidos socialmente para a obtenção de um trabalho como professor.

A formação continuada de professores apresenta-se como objeto de estudo. A organização do trabalho docente em escolas - públicas ou privadas, nos seus diferentes níveis e modalidades - está diretamente implicada com a formação continuada de professores. Ela aparece associada não só ao acesso ao mercado de trabalho, mas também à manutenção do emprego conquistado. Essa dimensão pode ser compreendida pela noção de capital humano construída por Becker (1993). Ou seja, trata-se da soma de aptidões e saberes acumulados pelos indivíduos ao longo da vida e uma fonte de capacidades produtivas que o mercado de trabalho valida sob a forma de expectativa de ganho ao longo da vida ativa. Ser formado ou se formar no exercício do trabalho docente é manter e desenvolver o capital humano, para melhorar na carreira e o salário, ou mesmo para se manter trabalhando. Há outra dimensão na formação continuada que é a de garantir a performance da escola. Assim, a educação e a formação são não somente objeto de pesquisa, como também de inovação das condições de sucesso escolar dos estudantes.

O presente texto está organizado em oito partes. Na primeira trato da educação na perspectiva da globalização. Na segunda, apresento um estudo sobre o Banco Mundial e a educação. Já a terceira parte aborda o que é formação continuada de professores, para, em seguida, expor a visão do Banco Mundial em relação à expressão professores excelentes. As duas partes seguintes trazem a formação continuada de professores no discurso da excelência e o discurso do Banco Mundial no tocante a essa formação. Finalizando, temos as considerações.

\section{A EDUCAÇÃO NA PERSPECTIVA DA GLOBALIZAÇÃO}

$\mathrm{Na}$ lógica da economia globalizada, o Banco Mundial atua como agência de empréstimos, reguladora do capitalismo, muito menos como agência de doações "donor" (Torres, 2005, p. 17). Seu papel ao longo dos anos caracteriza-se como instituição financeira, agência de empréstimos financeiros. Com base em Bujazan et al. (1987), Torres (2005, p. 21) afirma o componente político do Banco Mundial referente à concepção da ideologia estadunidense, bem como às necessidades e intenções do empresariado daquele país. Ao aceitarem empréstimos e orientações gerais dos organismos multilaterais, os países sujeitam-se às condições de ajuste de contas, medidas e avaliações (Cury, 2017, p. 19). 
A ocidentalização do mundo como possibilidade explicativa da globalização (Ianni, 2003, p. 24) constitui-se na instauração de agendas econômicas para o mundo em desenvolvimento, por padrões econômicos e valores socioculturais (Ianni, 2003, p. 98). Nos anos de 1990, efetivaram-se as agendas pela perspectiva de mercados hegemonizados pelos Estados Unidos e pela Europa Ocidental. Feldfeber e Gluz (2011, p. 341) apontam que houve um processo ocorrido em toda a América Latina de reformas educativas durante a década de 1990 que envolveu descentralização, privatização e desregulamentação dos serviços sociais implementados em quase todos os países latino-americanos.

A predominância do fator econômico sobre o social, na perspectiva das autoras, constitui um padrão das reformas educacionais. Os conglomerados econômicos e o sistema financeiro ditam as regras. A lógica do mercado expressa-se na produção, no consumo e na manutenção da economia mundial, e não mais nacional; desconsideram-se as características, as necessidades dos países, das regiões, dos locais. A ocidentalização do mundo coincide com o processo de modernização, por suposição de "que tudo que é social se moderniza ou tende a modernizar-se" (Ianni, 2003, p. 99), quando o que vale é o atendimento à nova ordem da economia ocidental. A modernização traz consigo a ocidentalização pelos padrões, pelos valores e pelas instituições predominantes na Europa Ocidental e nos Estados Unidos (Ianni, 2003, p. 98-99).

A modernização, uma dimensão do mundo moderno, organiza as relações da vida em sociedade pela perspectiva da economia de mercado estadunidense e da Europa Ocidental. A produção dos bens e serviços está vinculada à lógica do consumo, e, para isso, o trabalho intensifica-se a fim de atender à necessidade da produção ampliada, modernizada.

Justifica-se a globalização pelo viés econômico. O fator de integração dá-se pela lógica da economia, em que há predominância de bens, serviços, capital, tecnologia e no campo das ideias, de acordo com David Dollar (apud Charlot, 2007, p. 132), executivo do Banco Mundial. Dessa maneira, o fenômeno econômico prevalece sobre os aspectos da vida contemporânea, como forma de manutenção dos anseios dos conglomerados econômicos, capitaneados pelos organismos internacionais (Charlot, 2007, p. 132).

As relações entre fenômenos econômicos, produção e consumo de bens, serviços, tecnologia e ideias configuram a globalização. O Banco Mundial, como instituição bancária, uma das representantes da ocidentalização do mundo, refere-se à educação tal qual possibilidade de manutenção da ordem econômica globalizada. Esse banco trabalha com evidências, com base em dados que indicam o que alavanca a educação em países como Estados Unidos e Europa Ocidental. Os estudos elaborados pelo seu corpo técnico indicam que a tecnologia e a formação continuada dos professores são ferramentas para a melhoria da qualidade da educação escolar. Trata-se de uma recuperação do tecnicismo de 1970. Expressões como prática operacional, treinamento de professores e tecnologia educacional norteiam o discurso oficial do Banco Mundial, haja vista o pronunciamento do presidente do Grupo Banco Mundial no prefácio do Relatório/2018 (Banco Mundial, 2018, p. xii). 
Se as evidências apontam para a técnica, o como fazer, para que os estudantes aprendam, o software é uma ferramenta, no jargão do tecnicismo, auxiliar para que os estudantes, ao se ajustarem ao seu próprio ritmo, também o façam em relação aos seus questionamentos levando em conta o desempenho contínuo (Banco Mundial, 2018, p. 134). É possível afirmar que as tecnologias são um fim em si mesmas. A escola constituiria o espaço privilegiado para formar trabalhadores qualificados para operar as novas tecnologias. Conformam-se os estudantes, os professores e a escola à lógica da globalização e, por conseguinte, do mercado.

A predominância do técnico sobre a inteligência e a imaginação, que caracterizam a era da informática, movimenta o mundo (Ianni, 2003, p. 126).

$\mathrm{Na}$ educação, a tecnologia orientaria a prática e assistiria o professor para que a aprendizagem dos estudantes fosse garantida para o mercado globalizado. Informatização e eletrônica atuariam como constituintes do sistema nervoso humano (Lima, 2015, p. 415-416), bem como os meios se adequariam aos fins e se modelariam indivíduos, tornando-os aptos a operarem no mundo globalizado. A consecução da racionalidade econômica do mundo globalizado seria mantida.

O domínio da tecnologia produziria mão de obra qualificada para operar as máquinas e ferramentas modernas na aldeia globalizada. São cada vez mais numerosos os pacotes de softwares educacionais disponíveis no mercado, como ferramentas que o professor utiliza para dinamizar suas aulas, bem como alavancar a aprendizagem. A tecnologia organizaria a produção, pelos instrumentos, esquemas e inventos que instauram a era da máquina, um jeito de esquematizar e manter as relações, quer sejam sociais, quer políticas, perpetuando padrões e comportamentos - instrumento para o controle e a dominação (Marcuse, 1996 apud Ianni, 2003, p. 103).

Se à educação cabe esse papel, o Banco Mundial, em relação à educação, transforma-se no Ministério da Educação dos países do sul. Nesse sentido, redesenha as instituições, redefine o conteúdo educacional pelos ditames da economia. A educação está no centro das propostas do Banco Mundial, para a inexorável globalização. Aprofunda, portanto, a exclusão estrutural nos países chamados do sul (Leher, 1998, p. 9).

A educação adquire relevância nas proposições do Banco Mundial. Assim, está a serviço da manutenção da lógica empresarial, do mercado globalizado, entretanto é possível uma educação para além do capital, afirma Feldfeber (2014).

Construíram-se significados alternativos pela educação ante a lógica do capital. Outros mundos são possíveis. Ao trazer para o centro a política e a educação enquanto ato político, objetivo questionar uma lógica que é tecnocrática, que nos impõe tanto a discussão apenas de conteúdos básicos, definidos, quanto como medimos como melhorar a gestão das escolas, desconsiderando o que significam a educação e seus propósitos (Feldfeber, 2014, p. 150-151).

A disputa pela hegemonia predomina a lógica do Banco Mundial pela predominância do mercado. Está em jogo a manutenção de uma forma de conceber o mundo, ocidentalizado e globalizado.

O mundo ocidentaliza-se a partir dos Estados Unidos e da Europa Ocidental e de seus organismos multilaterais, sustentáculos da modernização. O Banco Mundial é uma instituição que, por excelência, traduz as concepções de que a 
modernização é portadora da noção de progresso, inovação e empreendedorismo. O mundo globalizado é sinônimo de ocidentalização, sem esquecer que no ideário da teoria da modernização estão presentes a democracia, os direitos de cidadania, a institucionalização das forças sociais em conformidade com padrões jurídico- políticos de negociação e acomodação, o estabelecimento das condições e dos limites das mudanças sociais, as garantias contra as ideias revolucionárias traduzidas em práticas, a precedência da liberdade econômica no tocante à política, a primazia da cidadania política em face da social e cultural (McClelland, 1976; MacPherson, 1990; Marshal, 1967 apud Ianni 2003, p. 99-100).

A modernização apresenta-se como inexorável. As dimensões econômica e política constituem o processo de globalização dos mercados. A economia é o mote para as relações que se estabelecem e, nessa direção, o mercado dita as regras desse convívio. A modernização organiza a vida em sociedade e interfere nas políticas sociais para adequá-las à lógica econômica. A educação como política social e a formação continuada de professores respondem a essa racionalidade econômica que submete as relações sociais, políticas e culturais ao mercado globalizado, ocidentalizado, dito moderno.

\section{O BANCO MUNDIAL E A EDUCAÇÃO}

O capital humano é central nas recomendações do Banco Mundial para a economia globalizada, porque possibilitaria a conformação dos trabalhadores para o mercado. Para o banco, o capital humano está perdido, por causa de uma crise que denomina de moral e econômica. Isso advém da sociedade fracassada, resultado da não aprendizagem dos estudantes, relegados à pobreza e exclusão. Como vivemos sob a égide da economia de mercado, a perda do capital humano refletiria no desenvolvimento da sociedade. Com isso, o futuro estaria ameaçado. Palavras do presidente do Banco Mundial, no prefácio do Relatório/2018 (Banco Mundial, 2018, p. xi).

O desenvolvimento econômico seria respaldado pelo investimento em educação. A melhora nos rendimentos escolares individuais adviria desse crescimento, cujo efeito seria sentido nas relações sociais, culturais e políticas. A importância da educação para todos os cidadãos, por meio de planos de governo, permitiria a melhoria de qualidade de vida da população. Essa dimensão encontra adesão de diferentes analistas. Há uma relação necessária entre educação, cidadania, qualidade de vida e políticas governamentais, mas ela não é suficiente (Becker, 1993, p. 35).

O capital humano, para Becker (1993, p. 9), traduz-se por investimento nas pessoas. Guarda relação com o rendimento financeiro e atua no campo psíquico pelos recursos indivíduos. É uma relação de mão única. Do mercado para com as pessoas. As relações entre investimento em educação e retorno podem ser mensuradas pelos rendimentos daí advindos. Entretanto, ao observar dados do mercado de trabalho, essa relação não se confirma. Professores que possuem longa formação escolar têm baixos rendimentos salariais.

O capital humano eleva, por meio da educação, a possibilidade de um trabalhador se adequar às necessidades do mercado, porque instaura a produtividade mediante o que é aprendido na escola para a vida laboral. 
No Relatório/2017, o Banco Mundial explicita que o capital humano é investimento nas pessoas, para que os países prosperem no século XXI. Trata-se do capital em atendimento às questões de crescimento econômico dos países. Pela educação, elavam-se o capital humano, a produção, a renda, bem como o emprego e o crescimento econômico (Banco Mundial, 2017, p. 1 e 38). A sociedade com base na economia de mercado requer trabalhadores capacitados para operar nesse cenário, desde em atividades manuais até em atividades intelectuais e de direção de empresas.

No Brasil, na década de 1990, a concepção de educação como capital humano foi retomada pelo governo de Itamar Franco e consolidada no de Fernando Henrique Cardoso (FHC). Com a Declaração Mundial sobre Educação para Todos (Conferência de Jomtien - 1990), os organismos internacionais, juntamente com os governos e o empresariado, apresentaram proposições acerca da aprendizagem (Unicef, [1990?]). A satisfação das necessidades básicas de aprendizagem na lógica econômico-empresarial propõe políticas públicas e curriculares de formação mínima de trabalhadores para o mercado. A leitura, a escrita, a expressão oral, o cálculo, a solução de problemas são as necessidades essenciais para a aprendizagem, também como os conhecimentos, as habilidades, os valores e as atitudes (Unicef, [1990?]). A educação para todos, conformados à globalização, é uma promessa política que o Banco Mundial patrocina e integra. Iniciada em Jomtien em 1990, reafirma os Objetivos de Desenvolvimento do Milênio da Organização das Nações Unidas (ONU), aprovados por praticamente 200 países.

Após a Conferência de Jomtien, na gestão de Itamar Franco, o Ministério da Educação (MEC) elaborou o Plano Decenal de Educação para Todos (1993/2003), o qual não foi implementado, apesar de constituir um trabalho integrado das esferas do legislativo, do executivo e do judiciário. $\mathrm{O}$ documento, em atenção às necessidades dos organismos multilaterais, orientou, não obstante, ações esparsas na esfera federal (Saviani, 1999, p. 129).

Ao longo dos anos seguintes, já no governo de FHC, essa ação originou o movimento da iniciativa empresarial Todos pela Educação, com o propósito de influenciar as políticas públicas educacionais, na perspectiva econômico-empresarial. $\mathrm{O}$ empresariado organizado no movimento Todos pela Educação atende a orientações dos organismos multilaterais, em que nos contextos nacionais predominam seus objetivos, externos aos referidos contextos, mas em conformidade com o externo, ou seja, os organismos multilaterais. É o movimento de instalação: os objetivos são forjados em organizações internacionais e, em seguida, instalados em espaços locais (Feldfeber e Saforcada, 2012, p. 16).

O Plano Decenal de Educação para Todos sustenta a lógica da globalização. Todos serão formados, treinados e conformados pelas orientações do sistema global advindas de organismos internacionais. As mentes, as ações e as necessidades dos cidadãos moldam-se aos interesses da economia de mercado. Importante faz-se explicitar o que é a formação continuada pela lógica do mercado.

\section{FORMAÇÃO CONTINUADA DE PROFESSORES}

A formação continuada de professores que defendo são ações das quais o trabalhador participa, em que se atualiza, se aperfeiçoa, amplia seus conhecimentos construídos na formação inicial, a graduação, e na experiência. Suas características são: 
- articulação com a formação inicial;

- organização em um continuum de ações;

- proposição e desenvolvimento pelas instituições de formação;

- demanda dos próprios professores ou dos dirigentes e instituições;

- compreensão da organização do trabalho, do estatuto da profissão;

- não é a única via para melhorar a qualidade da escola (Moreto, 2018, p. 42).

Essa concepção de formação continuada de professores encontra respaldo nas Diretrizes Curriculares Nacionais para a formação inicial e continuada (Brasil, 2015, p. 13), em que o artigo 16 afirma o caráter coletivo, organizacional e profissional. Assevera a necessidade de considerar o processo pedagógico dos saberes e valores. As atividades de formação constituem ações que ultrapassam a formação inicial, requerida para o magistério, consistindo-se em formas de reflexão, aperfeiçoamento técnico, com os componentes ético e político da profissão de professor.

Concepções como aperfeiçoamento técnico e gestão da sala de aula expressas pelo Banco Mundial encontram ressonância nas Diretrizes Curriculares Nacionais. O parágrafo único do artigo 16 expressa a formação continuada para o desenvolvimento profissional, considerando o projeto pedagógico das escolas, os problemas e os desafios do contexto; a inovação e o desenvolvimento; o protagonismo do professor; e o diálogo e a parceria, contribuindo para "alavancar novos patamares de qualidade ao complexo trabalho de gestão da sala de aula e da instituição educativa" (Brasil, 2015, p. 14).

As diretrizes deixam de levar em conta o aperfeiçoamento profissional para a melhoria do trabalho docente.

Gatti e Barreto (2009, p.13) afirmam que no campo da formação continuada de professores há vasta produção teórica e empírica a respeito. As autoras elaboraram um balanço em relação a quantas anda a formação de professores para a educação básica no Brasil. Constataram nos estudos e pesquisas analisados que se tem uma interpretação de formação continuada que "decorre de políticas que priorizaram a formação em serviço por indução de organismos multilaterais, que estimularam, via financiamento, este tipo de formação" (Gatti e Barreto, 2009, p. 209).

O Banco Mundial, como um organismo multilateral, assevera uma formação continuada de caráter aplicativo-transmissivo, ou seja, por meio de lições-modelo, da ortodoxia, do professor eficaz e das competências para ser um bom professor (Imbernón, 2001, p. 60). A aplicação da proposta do Banco Mundial, por meio da transmissão, concretiza-se por dois modelos, em que as ações se organizam no sentido de melhorar o ensino: o primeiro refere-se ao comportamento humano, e o segundo trata do "treinamento individual e repetido para professores, com acompanhamento pelo instrutor" (Banco Mundial, 2018, p. 132).

Gatti e Barreto (2009, p. 201-202) afirmam que os professores estão ausentes nas diferentes instâncias de decisão, e sua participação é limitada nos momentos de definição de políticas e projetos, tendo a escola como centro.

Caetano (2013, p. 226) estudou as representações de formação continuada em 16 professoras dos anos iniciais do ensino fundamental de Vitória (ES). Observou 
que elas avaliavam o caráter de externalidade, de ausência de participação delas, assim como não contemplavam suas demandas nem especificidades.

A formação continuada, na perspectiva do paradigma aplicativo-transmissivo, evidencia a perpetuação de práticas descompromissadas com as necessidades dos professores e das instituições educacionais locais.

A formação continuada de professores não deveria ser concebida à margem das instituições concretas em que se desenvolvem cotidianamente as práticas pedagógicas (Feldfeber e Imen, 2006, p. 171).

Em contraste com o paradigma aplicativo-transmissivo que desconsidera os professores como possíveis interlocutores, na formulação de programas e ações para a formação continuada de professores, a escola torna-se o locus privilegiado de onde emanam as necessidades a serem atendidas pela formação continuada.

O paradigma aplicativo-transmissivo, em consonância com o domínio de técnicas para atuar em sala de aula em situação futura, atende às proposições do Banco Mundial. As referidas proposições estudaremos a seguir.

\section{AS POLITIICAS DO BANCO MUNDIAL A RESPEITO DA FORMAÇÃO CONTINUADA DE PROFESSORES}

A formação continuada de professores para o Banco Mundial baseia-se na formação por competências, um viés comportamental que compreende o treino, a prescrição, a aplicação e as técnicas de ensino e aprendizagem.

Por meio do treinamento, os professores, aperfeiçoados tecnicamente para a gestão da sala de aula, instrumentalizariam os estudantes, pelas habilidades e competências necessárias para a inserção no mercado de trabalho, a serem trabalhadores flexíveis, e estes se adaptariam às necessidades do mercado. Com o domínio das habilidades, técnicas e competências, produziriam mais e melhor em qualquer situação. Professores motivados e com habilidades: a lógica do banco.

\section{PROFESSORES MOTIVADOS E COM HABILIDADES}

As habilidades fazem parte do modus vivendi da competição da inserção no sistema de mercado, da nova razão do mundo, a qual se normativa pelo jeito como se vive. $\mathrm{O}$ próprio indivíduo acaba por se comportar como se fosse uma empresa, uma empresa de si próprio (Cury, 2017, p. 20-21). A produção intelectual do banco enfatiza esse jeito de viver as relações no mundo do trabalho. Os professores, por conseguinte, estão afeitos a isso.

Os professores, nos documentos do Banco Mundial, têm sido vistos como peça-chave no que se refere a melhorar os índices de aprendizagem dos estudantes. Desde Prioridades y estrategias para la educación (Banco Mundial, 1996, p. 4), os professores são considerados um insumo educacional como tantos outros. Tais documentos asseveram, ainda, que a combinação ineficiente dos insumos poderia contribuir com o baixo nível de aprendizagem e abandono dos alunos. Em outro documento, sob a chancela do Banco Mundial, aquele produzido por Popova, Evans e Arancibia (2016, p. 2), os autores afirmam que os professores 
"têm sido considerados os mais importantes determinantes da aprendizagem dos estudantes". Nesse sentido, o Banco Mundial prioriza a formação continuada dos professores nos moldes descritos, porque deles depende a formação dos futuros trabalhadores flexíveis.

A formação continuada defendida por Popova, Evans e Arancibia (2016, p. 2), por conseguinte, pelo Banco Mundial, refere-se ao "desenvolvimento profissional [pois] pode, quando projetada corretamente, melhorar a aprendizagem do aluno".

O Banco Mundial concebe, portanto, a aprendizagem como o elemento fundamental no processo educacional, haja vista o título do Relatório/2018 (Banco Mundial, 2018): “Aprendizagem: para realizar a promessa da educação”. Não importam fatores histórico-sociais das populações. O que importa é a aprendizagem que conforme os futuros trabalhadores adaptados às necessidades do mercado. A promessa realizar-se-ia com a priorização do aprendizado, menos do que com a escolaridade, segundo o presidente do Banco Mundial, no prefácio do Relatório/2018 (Banco Mundial, 2018, p. xii).

O relatório aponta, ainda, três estratégias complementares para "alcançar a aprendizagem para todos":

- a avaliação da aprendizagem, que criaria incentivos para a reforma. Todavia, a aferição da aprendizagem é insipiente em determinados países;

- o que as escolas ensinam e como ensinam. A necessidade de elas aprenderem para trabalharem. Há uma expansão do conhecimento da didática, de como os alunos aprendem com mais eficiência, porém as escolas não trabalham da mesma forma. Seria necessário utilizar abordagens que têm as evidências como padrão;

- a homogeneização da atuação dos professores, com o objetivo da aprendizagem na escola (Banco Mundial, 2018, p. xii).

O capítulo 6 do Relatório/2018 organiza-se de acordo com temas como: a ineficácia de parte da formação de professores, apesar de algumas abordagens funcionarem; a ajuda aos professores a ensinar ao nível do aluno; e a motivação e os incentivos para os professores. Esses temas, compondo um capítulo do relatório, sinalizam o tratamento a ser dispendido às habilidades e a motivação para a consecução das políticas econômicas globalizadas.

O preparo e a motivação dos professores indicam que estão "equipados e motivados". Seriam o "ingrediente" sem o qual não haveria aprendizagem (Banco Mundial, 2018, p. 131). As habilidades e a motivação adequam os profissionais às demandas da economia globalizada, porque os subordinam aos mecanismos da produtividade e, por conseguinte, da lógica do mercado. Trata-se das habilidades e da motivação para o trabalhador ser produtivo pela assimilação de informações e de saber manuseá-las para agir com competência.

A concepção do Banco Mundial, de que professores enquanto ingredientes equipados e motivados corroboram com a degradação do exercício da profissão docente, expressa, na visão de Freitas (2012, p. 96), pela baixa qualidade da formação, condições inadequadas de trabalho, remuneração insuficiente, ausência de carreira 
e de jornadas de trabalho. A afirmação de Freitas (2012, p. 96) constitui o universo das escolas públicas de há muito.

A motivação e a orientação dos e aos professores, independentemente das condições expressas anteriormente, são evidências para o Banco Mundial. Acresce-se a elas a necessidade de domínio do conteúdo. $\mathrm{Na}$ busca por garantir essas características profissionais, há sistemas educacionais que deixam a desejar, porque os denominados momentos de "desenvolvimento profissional" são teóricos e inconsistentes (Banco Mundial, 2018, p. 131). Confirmam essa avaliação do Banco Mundial Popova, Evans e Arancibia (2016, p. 18), porque supõem a ineficiência dos programas de treinamento de professores: "E possível que muitos sejam ineficientes", apesar do orçamento e do tempo destinado a eles. Criticam até mesmo o fato de que acontecem, em alguns casos, simultaneamente diversos programas. A seguir, tem-se como é a formação que o banco preconiza.

\section{A FORMAÇÃO CONTINUADA DE PROFESSORES QUE FUNCIONA PARA O BANCO MUNDIAL}

O Relatório/2018 (Banco Mundial,2018,p.131) aponta que a formação deve ser para cada professor, referente à sua sala de aula e por repetição de estratégias de como e o que ensinar, além da aplicabilidade do que se aprendeu nos treinamentos, verificada por meio do acompanhamento pelos treinadores, e, por fim, da atenção à motivação dos professores pelos incentivos recebidos.

Os aspectos como individualização e repetição, acompanhamento e didática específica, juntamente com a motivação, dariam conta de treinar os professores. $\mathrm{O}$ professor funcionaria bem para o sistema se treinado na sua especificidade, individualizado, com o foco na repetição das técnicas aprendidas, tendo um supervisor que o treinou acompanhando a sua atuação, seu comportamento em sala de aula, quando do uso de estratégias e materiais adequados oriundos do treinamento. Soma-se a isso a motivação. Os professores motivados interessam, porque produzem mais.

Ainda quanto ao Relatório/2018 (Banco Mundial, 2018, p. 131), no subitem "A maior parte da formação de professores é ineficaz, mas algumas abordagens funcionam", existe o questionamento de que se haveria esperança no treinamento em serviço ou desenvolvimento profissional: "decididamente sim". Nesse aspecto, o relatório no trabalho de Popova, Evans e Arancibia (2016, p. 3), bem como o de Burns e Luque (2014, p. 3-6), vale-se da comparação com outros países, principalmente os Estados Unidos e da Europa Ocidental. Isso indica aos países do sul a se adequarem ao que deu certo em outras localidades. Agindo assim, os países conseguirão excelência na educação e, por conseguinte, obter recursos com o banco para seus programas. Alinham-se os países às necessidades da lógica do mercado e, consequentemente, da globalização.

No Relatório/2018 (Banco Mundial, 2018,p. 133) há tabelas e quadros para as comparações. Por exemplo, na Tabela 6.1, "Modelos de comportamento humano que podem orientar ações para melhorar o ensino: alguns exemplos", tem-se a comparação de dados dos Estados Unidos, da Índia e do Quênia (Banco Mundial, 2018, p. 132). No Quadro 6.2, "O que funciona no treinamento de professores antes da contratação”, os dados são da cidade de Nova York. 
O documento de Popova, Evans e Arancibia (2016, p. 6) apresenta em um dos subtópicos “o que funciona em países de alta renda”, em relação à formação de professores. Para essa constatação, lança mão de dados sobre os Estados Unidos, no tocante a programas de formação continuada de professores.

Comparam-se países. Os do sul, que necessitam se alinhar ao banco, com os que já se afinaram com a lógica, como o Chile, na América Latina. A comparação é no sentido de explicitar o caminho já percorrido pelo modelo. Países como o Chile são modelo para o Banco Mundial na perspectiva da excelência, haja vista também a comparação feita com os asiáticos Singapura e Coreia, nos relatórios do banco. O caso chileno é emblemático para a América Latina, porque representa onde as políticas neoliberais se instalaram com êxito para os programas do Banco Mundial. Feldfeber, Assael e Oliveira (2017, p. 2) apontam que o modelo chileno implementado desde os anos de 1980, período da Ditadura de Pinochet, serviu de referência de sucesso para os países da região. De acordo com a orientação do mercado, incorpora a lógica de mecanismos de mercado ao campo da educação: a competição, os resultados de aprendizagem e o pagamento pelo mérito dos professores.

Ianni (2003, p. 50) lembra que as chamadas "economias-mundo" se baseiam nas diversidades e desigualdades, as quais se constituem pelos aspectos social, político, cultural e econômico. Todavia, a comparação expressa pelo Relatório/2018 (Banco Mundial, 2018) respalda a perspectiva defendida pelos técnicos do banco na manutenção dos interesses das grandes corporações, na efetivação da ocidentalização do mundo.

Naquilo que funcionaria para o Banco Mundial, Popova, Evans e Arancibia (2016, p. 7) orientam os países do sul a seguirem os padrões do norte, os considerados pelos autores como de "alta renda", em que os professores mais experientes orientariam os iniciantes, compartilhando planejamento e participando da tomada de decisões. Os que têm mais indicam aos que têm menos.

A formação continuada de professores que serve ao Banco Mundial é apresentada por Popova, Evans e Arancibia (2016, p. 7). Os autores afirmam a eficácia dos programas de treinamento desde que haja vista o currículo prescrito com base na eficácia e na eficiência estabelecidas pelo Banco Mundial. Determinam um método específico, detalhando instruções para a implementação, o acompanhamento para os professores, e um modelo de coaprendizagem dos alunos se daria na conformação com os modelos aprendidos nos treinamentos dos professores.

$\mathrm{Na}$ perspectiva de indicar a formação que funciona com base em modelos, Popova, Evans e Arancibia (2016, p. 6) afirmam que nos Estados Unidos estudos asseguram a eficácia em programas que prescrevem o ensino de conceitos concretos, da avaliação, da observação e da reflexão, em oposição ao ensino de conceitos abstratos. Essa concepção de ensino, firmada nos manuais de treinamento, é a defendida pelo Banco Mundial.

Os conceitos abstratos oportunizariam a aprendizagem de aspectos sócio-históri$\cos$, conceitos relativos à humanidade, por exemplo, que emancipariam os estudantes da sua condição de futuros trabalhadores flexíveis. 
Os autores defendem, ainda, a constância no apoio contínuo e significativo, não por oficinas pontuais (Popova, Evans e Arancibia, 2016,p. 132). Praticidade, especificidade e continuidade são componentes da concepção técnica, daquela que leva à praticidade.

Popova, Evans e Arancibia (2016,p. 2), tomando por base uma análise de 171 projetos apoiados pelo banco relativos à educação (de 2000 a 2012), afirmam que a atualidade e a eficácia dos programas permanecem limitadas, bem como o caráter "superteórico". As formações não dão conta de atender às exigências da economia globalizada, referendada pelo Banco Mundial.

Para constatar se o que ensinaram nos momentos do treinamento é colocado em prática, até mesmo como forma de garantir o atendimento às necessidades do mercado, os professores são monitorados.

\section{AS VISITAS DE ACOMPANHAMENTO: O ENQUADRAMENTO DOS COMPORTAMENTOS}

Uma ação realçada pelo Relatório/2018 (Banco Mundial, 2018, p. 132) refere-se às "visitas de acompanhamento na escola". Os profissionais que ministraram o treinamento se deslocam até os professores, para acompanharem o seu trabalho. Essa é uma ação de continuidade, quando os professores são observados em situação de sala de aula, para constatar se implementam os novos métodos aprendidos no treinamento.

$\mathrm{Na}$ Tabela 6.1, "Alguns exemplos de modelos de comportamento humano que podem guiar para incrementar o trabalho do professor", um dos princípios a que se refere o modelo é o treinamento com acompanhamento em sala de aula. Comparam-se, novamente, os países, pois se afirma que na Índia o programa com acompanhamento repetitivo elevou o nível de aprendizagem dos estudantes (Banco Mundial, 2018, p. 132).

Uma boa prática de treinamento de professores em serviço envolve visitas de acompanhamento às salas de aula dos professores para fornecer suporte contínuo (Banco Mundial, 2018, p. 133).

Burns e Luque (2014, p. 42), na busca por explicitar razões para o trabalho dos professores não atingir resultados esperados, baseiam-se nas observações de sala de aula, que mostram o despreparo dos professores.

O Relatório/2018 (Banco Mundial, 2018) fundamenta-se nos dados da pesquisa de Popova, Evans e Arancibia (2016, p. 3), em que asseveram a inexistência de instrumento para avaliar a eficácia dos treinamentos a fim de "melhorar o comportamento do professor". Prosseguem constatando o desconhecimento de "quais componentes específicos desse treinamento efetivamente melhoram o comportamento do professor e, subsequentemente, o aprendizado do aluno" (Popova, Evans e Arancibia, 2016, p. 3).

O professor que tiver sua sala de aula acompanhada pelo supervisor, que muitas vezes é o próprio diretor da escola, ou o formador do professor, desempenhará melhor o seu trabalho, porque observado. Atende, dessa maneira, às necessidades dos manuais prescritivos dos processos de formação orientados pelos organismos internacionais.

Aqui se explicita a racionalidade em que a técnica se expressa como fundante da relação do profissional com a sua profissão. Se dominar a técnica, será um excelente profissional. Há uma racionalidade na formação pela técnica a que 
submete tudo aos fins, àquilo que se quer alcançar. No caso aqui, a subordinação aos ditames da globalização.

\section{A FORMAÇÃO CONTINUADA DE PROFESSORES QUE FUNCIONARIA PARA O BANCO MUNDIAL}

Outra evidência do Relatório/2018 (Banco Mundial, 2018, p. 133) refere-se a "O que funciona no treinamento de professores", como: o desempenho dos alunos, as visitas de acompanhamento e o roteiro de ações. Enquanto prescrição, as denominadas orientações específicas são importantes aos pouco qualificados. Estes, mesmo sob motivação, podem ser incapazes de atuar eficazmente. Funciona, ainda, apresentar a esses professores planos de aula elaborados pelos níveis centrais, com roteiro previamente prescrito.

Aparece em primeiro lugar como evidência a melhora do desempenho dos alunos, medida pelas avaliações em larga escala. Em seguida, vem a recomendação da boa prática avaliada pelas visitas de acompanhamento, quando os professores pouco qualificados teriam sua eficiência testada, para se tornarem mais eficazes. Posteriormente, há os planos de aula roteirizados. Se os alunos são avaliados, os professores também o são.

Popova, Evans e Arancibia (2016,p. 4-5) explicitam o que se considerar nos programas, tais como:

- a característica do professor que aprende;

- a característica do instrutor/supervisor, quem ensina;

- o modo de treinar;

- a duração do treino;

- o conteúdo da formação;

- o local em que ocorre a formação.

Esses fatores podem ser considerados como significativos para o desenho de uma política de formação de professores: professores técnicos, tempo de serviço, metas concretas e formações mais prolongadas - fatores técnicos e utilitaristas, componentes importantes para o Banco Mundial, características que garantiriam o profissional adequado às exigências do mercado, formado por professores excelentes.

\section{PROFESSORES EXCELENTES: AS ORIENTAÇÕES DO BANCO MUNDIAL AOS PAÍSES DO SUL}

Burns e Luque (2014, p. 2-3) indicam o porquê de se pensar a excelência para os professores da América Latina e do Caribe:

- a baixa qualidade média dos professores da região;

- o fraco domínio do conteúdo e práticas ineficazes;

- o Chile notabiliza-se em relação aos resultados dos alunos;

- a atenção para o recrutamento, a capacitação e a motivação de melhores professores;

- $\quad$ a elevação da qualidade com a redução da população em idade escolar; 
- o maior desafio é político, por conta dos sindicatos dos professores sempre ativos na região.

A responsabilização do professor, bem como o discurso do seu fracasso, resultados de uma formação inadequada aos padrões da globalização, é a tônica. Nos últimos tempos, após a reforma do Estado, retirou-se dos governos a responsabilidade pelas políticas e ela foi colocada como do professorado. Retirou-se, por conseguinte, a parcela de responsabilização dos órgãos centrais, dos organismos internacionais que financiam o padrão de um tipo de educação, a propalada pelo Banco Mundial, em que o capital humano é o mais importante insumo.

$\mathrm{O}$ aumento do capital humano apresenta-se como desafio, segundo Burns e Luque (2014, p. xi), para os países do nosso continente e o Caribe. Na concepção do referido capital, assim como para o Banco Mundial, a aprendizagem dos estudantes, menos do que os anos de escolaridade concluídos, compõe em parte os benefícios econômicos daquilo que foi investido em educação - a lógica do capital humano como fator preponderante para o mercado e a globalização.

Quem garantiria isso são os professores excelentes, importantes para o processo de ensino e aprendizagem. Todavia, há que se perguntar com quais parâmetros se avaliará a excelência de um professor. Pergunta recorrente, pois a lógica do Banco Mundial e dos organismos internacionais desconsidera como funciona a escola, bem como o trabalho dos professores (Charlot, 2007, p. 131).

Os trabalhadores precisam ser treinados para produzirem de forma a se ajustarem à lógica do mercado e da economia, em que os melhores, os mais preparados serão recompensados com o emprego. Eles vencerão a competição, que se baseia nos princípios da produtividade. Manter-se empregado significa manter-se atualizado, bem treinado, preparado para ser competitivo.

O desafio também se apresenta para os governos, de acordo com o Banco Mundial, em relação às associações dos professores, os sindicatos. Como o próprio documento afirma, "não é um desafio fiscal, nem técnico, mas político" (Banco Mundial, 2018, passim), porque os sindicatos têm força na América Latina. Os professores, ao lado dos profissionais da saúde, constituem nos sistemas de governo os maiores contingentes de trabalhadores. Assim sendo, sua representatividade sindical/de associação é considerável. A resistência desses trabalhadores às reformas se apresenta como impedimento ao avanço das políticas advindas da reforma do Estado.

É possível apreender que os autores assentam suas assertivas na perspectiva apontada pelo Banco Mundial. "Ao lado das peculiaridades socioculturais de cada tribo, clã, nação ou nacionalidade, desenvolvem-se as tecnologias e as mentalidades organizadas com base nos princípios da produtividade, competitividade" (Ianni, 1999, p. 187).

Vivemos em um mundo em transformação, em que as metas dos sistemas educacionais são permanentemente revistas, do enfoque na transmissão de fatos e memorização para a ênfase nas competências do estudante - para o pensamento crítico, a solução de problemas e a aprendizagem para a vida. As demandas sobre os professores são mais complexas do que nunca (Burns e Luque, 2014, p. 1). 
Não há o que negar quanto à transformação. O discurso da excelência marca presença nesse cenário como o das competências, das habilidades, da qualidade e das pedagogias do aprender a aprender. Professores excelentes não fogem a essa marca da competência para a qualidade requerida pelo mercado, pela economia. A produtividade é um elemento desse discurso. Os insumos educacionais - o currículo, a construção do prédio da escola, a aquisição de livros, o salário dos professores - culminam na interação do professor com os alunos no trabalho da sala de aula. O tempo utilizado em sala é fator da produtividade e, por conseguinte, do gasto com educação (Burns e Luque, 2014, p. 11).

O discurso da excelência exige do professor alcançar o sucesso, a superação e a conquista contínua da melhoria de si e dos estudantes. Nisso se constituiria o professor excelente, ou seja, o qual está continuamente aperfeiçoando-se, para ter sucesso em sua atividade de sala de aula. Ele busca sempre melhorar a sua performance e a dos estudantes, por meio de insumos externos à sala de aula, como, por exemplo, seguir o que lhe foi ensinado nos treinamentos e atender às exigências do que é prescrito pelo modelo de formação continuada ao que foi exposto. A excelência, nessa perspectiva, expropria do professor a possibilidade de pensar a respeito do seu trabalho. O professor excelente, nessa concepção, deixa de produzir conhecimento mediante a sua prática; simplesmente o reproduz.

\section{A FORMAÇÃO CONTINUADA DE PROFESSORES NO DISCURSO DA EXCELÊNCIA}

O que é o professor excelente já vimos na seção anterior. Agora nos interessa saber com que medida se avaliaria a excelência do professor? Isso se inscreve na investigação a que procedemos em relação ao estudo de Burns e Luque (2014).

Com base nos resultados da aprendizagem dos estudantes, uma das afirmações dos autores diz respeito ao envolvimento daqueles. "Os alunos não estão envolvidos". Prosseguem com a asserção de que isso pode estar relacionado "com o fracasso dos professores em manter os alunos envolvidos na aprendizagem" (Burns e Luque, 2014, p. 17).

Prosseguindo, Burns e Luque (2014, p. 17) afirmam que um dos "desafios" dos programas de formação de professores na América Latina e no Caribe, inicial ou continuada, é a manutenção dos estudantes no processo de aprendizagem, ou seja, equipar os professores com as estratégias de ensino na consecução da manutenção dos estudantes, assim como que se preparem para usar as estratégias com eficiência a todo momento.

Porque treinados, professores excelentes estariam equipados, para darem conta da aprendizagem. Menos importam questões do estatuto da profissão e de infraestrutura das escolas; o ensino, como se avalia, o que se avalia; as opções metodológicas, se nos referirmos à questão da didática. $\mathrm{O}$ tempo também é fundamental. Não se pode perder tempo. Em todos os momentos os professores necessitam ser excelentes. $\mathrm{O}$ aumento da eficácia dos professores em serviço e o emprego de incentivos que motivem os professores ao máximo esforço em todas as salas de aula devem ocorrer todos os dias, com todos os alunos (Burns e Luque, 2014, p. xi). 
As abordagens na formação devem ser diferenciadas e diferentes para a consecução do processo: exemplos de boas práticas gravados em vídeo e avaliação da prática dos professores em sala, quer seja por gravação em vídeo, quer seja por observação dos treinadores (Burns e Luque, 2014, p. 23).

Afinal, como é a preparação de professores excelentes? Quais são as etapas? Por que se trata de capacitação? Por que são incapazes, incapacitados? O banco orienta a capacitação que chamamos de utilitarista, porque treinados para aplicar.

Uma vez que os professores tenham sido contratados, é tarefa do sistema escolar torná-los eficazes.

Quatro tarefas essenciais são:

- indução: apoio na fase inicial da carreira;

- avaliação: regular os pontos fracos e fortes;

- desenvolvimento profissional: treinamento eficaz para correção dos pontos fracos;

- gestão: as necessidades dos professores e as das escolas e dos alunos, criando escolas eficazes (Burns e Luque, 2014, p. 34).

As tarefas indicam aos governos a adequação a um rol de prescrições haja vista o que seria um professor excelente. Para os governos terem o apoio do Banco Mundial e subsídios aos seus programas, os sistemas escolares necessitam cumprir com suas obrigações, pela realização das tarefas. Faz-se presente, nessas tarefas, o discurso da eficiência, pelo treinamento eficaz, que torne os professores eficientes; da competência, daqueles que têm o desempenho avaliado como melhor; pelo viés comportamental, porque serão regulados "os pontos fortes e fracos de cada professor" (Burns e Luque, 2014, p. 34); e as escolas se tornarão eficientes, porque contam em seu quadro com professores excelentes.

Naquilo que os autores chamam de indução, os "sistemas escolares" podem "aconselhar" os professores a deixarem a profissão. Isso apareceria como um estágio obrigatório em que se avalia o profissional. Orientam os sistemas a atentarem para a admissão de professores eficazes, assim como construírem um programa de indução à demissão, por meio do uso dos períodos probatórios (Burns e Luque, 2014, p. 34). Os professores ficam disponíveis, regidos pelas regras dos sistemas, em que os menos eficientes são aconselhados, induzidos a se demitirem. Não se trabalha no sentido de garantir a permanência dos incapacitados. Excluem-se os já excluídos.

Burns e Luque (2014, p. 37) referem-se aos treinamentos em serviço como uma rubrica com que mais se gasta, na gestão dos sistemas. Para tanto, a eficácia garantir-se-ia pela atenção ao conteúdo, à intensidade e à duração dos treinamentos, além da sua implementação.

O desenvolvimento profissional dos professores pode se dar pelas seguintes estratégias: abordagens orientadas, domínio do conteúdo, gestão da sala de aula e colaboração de colegas, todos oferecidos pelos treinamentos eficazes (Burns e Luque, 2014, p. 37).

Saber usar os materiais ou aprofundar conhecimento para ensinar de forma eficaz. A eficácia do professor em sala de aula, a observação e o aprendizado com o outro são competências que estabelecem parâmetros para que os sistemas de 
ensino e, por conseguinte, os governos adequem suas políticas a essas estratégias que tornam as escolas eficazes e os professores excelentes. Utilizam materiais que dariam conta de todo o tempo da aula, os quais manteriam os alunos envolvidos. O modernizante, modernizável, o que parece moderno guarda em si um quê de prático, pragmático, instrumental (Ianni, 2003, p. 103).

O professor excelente é avaliado pelo viés do utilitarismo, ou seja, se ele é capaz de exercer suas atividades docentes nos moldes forjados por intermédio das estratégias contidas no documento de Burns e Luque (2014). Significa ter competência pelo acúmulo do capital humano, que se consolidou ao longo dos anos, para utilizar estratégias e materiais adequados e dominar o conteúdo; apresentar conhecimento na matéria que ensina — ser um especialista —; empregar materiais, tempo e estratégias para que os alunos se envolvam na aprendizagem; e desenvolver o trabalho com base na prática com outros professores. A medida que o banco utiliza para avaliar se o professor é excelente é a mesma utilizada para dizer que as escolas são eficazes, na proporção em que uma grandeza interfere na outra. Ambas estão imbricadas e concorrem para a eficiência do modelo econômico do Banco Mundial com relação às políticas para a formação continuada de professores.

\section{CONSIDERAÇÕES}

Marca o processo de formação continuada estudada neste trabalho a racionalidade técnica, como, no caso aqui, por exemplo, o treino para ações futuras, o domínio de habilidades, a competência para as atividades em sala de aula ou para as ações para a atividade futura. Somam-se a isso o domínio da tecnologia, a preparação para o trabalho com modelo, o acompanhamento do trabalho em sala de aula e a adequação à prescrição de modelos de planejamento, que orientam os sistemas a se ajustarem às necessidades da economia globalizada, como os professores, pelo treino e pela técnica.

A racionalidade técnica construída no processo de globalização orienta a formação continuada de professores oriunda do Banco Mundial, pelas ações como o treinamento para a atividade futura. As pedagogias das competências - saber ser e aprender a aprender - integram essa racionalidade, tanto quanto o monitoramento da sala de aula. O planejamento roteirizado inclui-se nesse conjunto de prescrições racionais, que visam à manutenção da educação para a economia globalizada, avaliada pelo melhor desempenho dos alunos.

O padrão da formação pela racionalidade objetiva que os professores adquiram a técnica para ensinar pelo treinamento. $O$ professor consistiria em um técnico com ferramentas que lhe permitiriam, com o uso e o ensino das tecnologias, garantir a aprendizagem de crianças e jovens. $\mathrm{O}$ objetivo final é a aprendizagem.

O Banco Mundial demonstra a necessidade da aquisição de capital humano pelo acréscimo de instrução, treinamento e educação, enquanto capacidade de produção e manutenção do emprego no mundo globalizado. Seriam ajustes por parte de países considerados do sul,com a finalidade de participarem da lógica do progresso pelo viés econômico.

Pensar se as políticas de formação continuada de professores não funcionam oportuniza outra discussão. Não funcionam em relação a quê? Se não funcionam, qual é o motivo? Sozinha, a formação continuada não conseguirá formar os profes- 
sores. A não ser que seja para a manutenção da modernização e, por conseguinte, da globalização, para a manutenção da ordem econômica mundial, em que se retira a responsabilidade dos órgãos centrais e se responsabilizam os professores.

Há que se considerar as questões estruturais do magistério, como o estatuto dessa profissão. Necessário levar em conta, ainda, as condições de infraestrutura dos prédios escolares e a gestão vertical, em que os gestores das escolas têm a primazia sobre os demais funcionários e professores. Essas questões não fazem parte mais da agenda do Banco Mundial, porque o que garantiria a aprendizagem dos alunos é um professor bem treinado - por isso, excelente, em que a racionalidade técnica se constitui em discurso oficial, naquilo que objetiva a educação para o Banco Mundial: a aprendizagem dos estudantes.

\section{REFERÊNCIAS}

BANCO MUNDIAL. Prioridades y estrategias para la educación: examen del Banco Mundial. Washington, D.C.: Banco Mundial, 1996.

BANCO MUNDIAL. World Development Report 2017: ending poverty. Washington, D.C.: Banco Mundial, 2017. Disponível em: https://www.openknowledge.worldbank. org/bit-stream/handle/10986/27986/211119PT.pdf?sequence=9\&isAllowed=y. Acesso em: maio de 2018.

BANCO MUNDIAL. World Development Report 2018: Learning to Realize Education's Promise. Washington, D.C.: World Bank, 2018. Disponível em: https:// www.worldbank.org/en/publication/wdr2018. Acesso em: jun. 2018.

BASTOS, R. M. B.; ROCHA, A. R. M. A circularidade do autoreferencial teórico do Banco Mundial em suas pesquisas educacionais e seus projetos. Revista on line de Política e Gestão Educacional, v. 21, n. 2, p. 322-333, maio-ago. 2017. https://doi. org/10.22633/rpge.v21.n2.2017.9965

BECKER, G. S. Human capital: a theoretical and empirical analysis with special reference to education. 3. ed. Londres: University Chicago Press, 1993.

BRASIL. Conselho Nacional de Educação. Resolução CNE/CP no 02/2015, de 1o de julho de 2015. Define as Diretrizes Curriculares Nacionais para a formação inicial em nível superior (cursos de licenciatura, cursos de formação pedagógica para graduados e cursos de segunda licenciatura) e para a formação continuada. Diário Oficial [da] República Federativa do Brasil, Brasília, seção 1, n. 124, 2 jul. 2015. Disponível em: http://portal.mec.gov.br/docman/agosto-2017-pdf/70431-res-cne-cp-002-03072015pdf/file. Acesso em: 7 mar. 2015.

BURNS, B.; LUQUE, J. Professores excelentes: como melhorar a aprendizagem dos estudantes na América Latina e no Caribe. Washington, D.C.: Banco Mundial, 2014. Disponível em: https:/www.worldbank.org/content/dam/Worldbank/Highlights\%20 \&\%20Features/lac/LC5/Portuguese-excellent-teachers-report.pdf. Acesso em: fev. 2016. CAETANO, E. S. Formação contínua e percursos de desenvolvimento profissional: representações de professores do ensino fundamental no estado do Espírito Santo (Brasil). 2013. 343f. Tese (Doutorado em Educação) - Instituto de 
Educação, Universidade de Lisboa, Lisboa, Portugal, 2013. Disponível em: https:// repositorio.ul.pt/bitstream/10451/8640/1/ulsd65743_td_Eldimar_Caetano.pdf. Acesso em: jul. 2018.

CANÁRIO, R. Fazer da formação um projecto? Mudar as Escolas ou os Centros de Formação? Revista Portuguesa de Formação de Professores, v. 1, p. 55-63, 2001.

CHARLOT, B. Educação e Globalização: uma tentativa de colocar ordem no debate. Sísifo. Revista de Ciências da Educação, n. 4, p. 129-136, out./dez. 2007.

CURY, C. R. J. A globalização e os desafios para os sistemas nacionais: agenda internacional e práticas educacionais nacionais. Revista Brasileira de Política e Administração da Educação, v. 33, n. 1, p. 15-34, jan./abr. 2017. Disponível em: https:// seer.ufrgs.br/rbpae/article/view/72829/41182. Acesso em: jan. 2018.

FELDFEBER, M. La construcción del derecho a la educación: reflexiones, horizontes y perspectivas. Educação e Filosofia, Uberlândia, v. 28, n. esp., p. 139-153, 2014. Disponível em: http://www.seer.ufu.br/index.php/EducacaoFilosofia/article/ view/24607/15362. Acesso em: dez. 2018.

FELDFEBER, M.; ASSAEL, J.; OLIVEIRA, D. A. Hacia donde van las políticas educativas en América Latina? Megafón. La batalha de las ideas. CLACSO, n. 12/4, 2017. Disponível em: https://www.clacso.org.ar/megafon/images/megafon12/pdf/ Megafon_12_4_Myriam_Feldfeber.pdf. Acesso em: dez. 2018.

FELDFEBER, M.; GLUZ, N. Las políticas educativas en Argentina: herencias de los '90, contradicciones y tendencias de "nuevo siglo". Educação \& Sociedade, Campinas, v. 32, n. 115, p. 339-356, abr.-jun. 2011. Disponível em: http://www.scielo.br/pdf/es/ v32n115/v32n115a06.pdf. Acesso em: dez. 2018.

FELDFEBER, M.; IMEN, P. A formação continuada dos docentes: os imperativos da profissionalização em contextos de reforma educativa. Tradução Gênese de Andrade. In: FERREIRA, N. S. C. (org.). Formação continuada e gestão da educação. 2. ed. São Paulo: Cortez, 2006. p. 165-185.

FELDFEBER, M.; SAFORCADA, F. Políticas educativas y derecho a la educación en Argentina: un análisis de las metas educativas en el nuevo escenario latinoamericano. In: RAMBLA, X. (coord.). La Educación para Todos en América Latina: estudios sobre las desigualdades y la agenda política en educación. Buenos Aires: Miño y Dávila, 2012. Disponível em: https://ddd.uab.cat/pub/caplli/2012/174565/10_Feldfeber_ Saforcada_Politica_educativa_y_derecho_a_la_educacion_Argentina_a2012_postprint. pdf. Acesso em: dez. 2018.

FERREIRA, N. S. C. (org.). Formação continuada e gestão da educação. 2. ed. São Paulo: Cortez, 2006.

FREITAS, H. C. L. Formação de professores no Brasil: 10 anos de embate entre projetos de formação. Educação e Sociedade, Campinas, v. 23, n. 80, p. 136-167, set. 2002. https://doi.org/10.1590/S0101-73302002008000009

FREITAS, H. C. L. A (nova) política de formação de professores: a prioridade postergada. Educação e Sociedade, Campinas, v. 28, n. 100, p. 1203-1230, out. 2007. 
FREITAS, H. C. L. Formação inicial e continuada: a prioridade ainda postergada. In: OLIVEIRA, D. A.; VIEIRA, L. F. (org.). Trabalho na educação básica: a condição docente em sete estados brasileiros. Belo Horizonte: Fino Traço, 2012. p. 91-129.

FREITAS, H. C. L. PNE e formação de professores: contradições e desafios. Revista Retratos da Escola, Brasília, v. 8, n. 15, p. 427-446, jul./dez. 2014.

FUNDO DAS NAÇÕES UNIDAS PARA A INFÂNCIA (UNICEF). Declaração Mundial sobre Educação para Todos (Conferência de Jomtien -1990). Plano de Ação para satisfazer as Necessidades Básicas de Aprendizagem. Unicef, [1990?]. Disponível em: https://www.unicef.org/brazil/declaracao-mundial-sobre-educacao-para-todosconferencia-de-jomtien-1990. Acesso em: ago. 2018.

GATTI, B. A. Análise das políticas públicas para formação continuada no Brasil, na última década. Revista Brasileira de Educação, v. 13, n. 37, p. 57-70, jan./abr. 2008. https://doi.org/10.1590/S1413-24782008000100006

GATTI, B. A. (coord.); BARRETO, E. S. S. Professores do Brasil: impasses e desafios. Brasília: UNESCO, 2009.

IANNI, O. Globalização e Transculturação. Revista de Ciências Humanas, Florianópolis, v. 14, n. 20, p. 139-170, 1996. Disponível em: https://periodicos.ufsc.br/ index.php/revistacfh/article/view/23492/21159. Acesso em: jul. 2018.

IANNI, O. A era do globalismo. 4. ed. Rio de Janeiro: Civilização Brasileira, 1999.

IANNI, O. Teorias da Globalização. 11. ed. Rio de Janeiro: Civilização Brasileira, 2003. IMBERNÓN, F. Claves para nova formación del profesorado. Investigación en la Escuela, n. 43, p. 57-66, 2001. Disponível em: https://www.researchgate.net/ publication/39139762_Claves_para_una_nueva_formacion_del_profesorado. Acesso em: jul. 2015.

KUENZER, A. Z. As políticas de formação: A construção da identidade do professor sobrante. Educação \& Sociedade, v. 20, n. 68, p. 163-183, dez. 1999. https://doi. org/10.1590/S0101-73301999000300009

LEHER, R. Da ideologia do desenvolvimento à ideologia da globalização: a educação como estratégia do Banco Mundial para o alívio da pobreza. 1998. Tese (Doutorado em Educação) - Universidade de São Paulo, São Paulo, 1998.

LIMA, M. C. Globalização. In: GIOVANNI, G.; NOGUEIRA, M. A. (org.). Dicionário de políticas públicas. 2. ed. São Paulo: Fundap, Editora UNESP, 2015. p. 416.

MORETO, J. A. Formação continuada de professores: possíveis aspectos para a elaboração de um programa. In: MODESTO, C. M. S. (org.). Políticas públicas de educação: coletânea de pesquisas sobre a região metropolitana de Campinas. Campinas: Editora da Faculdade de Educação, 2018. p. 39-48. Disponível em: http:// www.bibliotecadigital.unicamp.br/document/?code=105277. Acesso em: 13 dez. 2018. POPOVA, A.; EVANS, D. K.; ARANCIBIA, V. Training teachers on the job: what works and how to measure it. Policy Research Working Paper No. 7834. Washington, D.C.: World Bank, 2016. Disponível em: https://openknowledge.worldbank.org/ handle/10986/25150. Acesso em: jun. 2018. 
QUEIROZ, M. I. P. O pesquisador, o problema da pesquisa, a escolha de técnicas: algumas reflexões. In: LANG, A. B. S. G. (org.). Reflexões sobre a pesquisa sociológica. 2. ed. São Paulo: Textos CERU, 1999. (n. 3, série 2.) p. 13-24.

SAVIANI, D. Sistemas de ensino e planos de educação: o âmbito dos municípios. Campinas-SP. Educação e Sociedade, ano 20, n. 69, dez. 1999.

TORRES, C. A. Conhecimento especializado, apoios externos e reforma educativa na época do neoliberalismo: um enfoque no Banco Mundial e na questão das responsabilidades morais na reforma educacional no Terceiro Mundo. Revista Lusófona de Educação, v. 5, n. 5, p. 15-36, 2005. Disponível em: http://revistas.ulusofona.pt/ index.php/rleducacao/article/view/1009. Acesso em: mar. 2018.

\section{SOBRE O AUTOR}

Julio Antonio Moreto é doutor em educação pela Universidade Estadual de Campinas (UNICAMP).

E-mail: glajuli@gmail.com

Recebido em 20 de março de 2019

Aprovado em 17 de abril de 2020 